\title{
OURICURI
}

\section{O PRINCÍPIO DA SUSTENTABILIDADE NA LEI DA MERENDA ESCOLAR}

\author{
Regina Cláudia do NASCIMENTO'1; Carlos Alberto Batista dos SANTOS2; Maria Regina de \\ Oliveira SILVA ${ }^{1}$; Meridiana Araújo Gonçalves LIMA ${ }^{2}$; Uliane Raimunda Nunes SÁ ${ }^{1}$
}
${ }^{1}$ Mestranda no Programa de Pós-Graduação em Ecologia Humana e Gestão Socioambiental - Universidade do Estado da Bahia - UNEB/DTCS Campus III, Juazeiro-BA. E-mail: regclaudia1@hotmail.com 2Professor (a) da UNEB/DTCS Campus III, Juazeiro-BA.
http://doi.org/10.29327/ouricuri.v8.i1.a2

Resumo: Dentro da perspectiva da sustentabilidade como um princípio constitucional, fundamental e social, fez-se uma revisão bibliográfica sobre temas que tratam da Lei da Merenda Escolar e do Princípio da Sustentabilidade, e a incidência desse princípio nos dispositivos do texto da Lei, apresentando como umas das alternativas para a sua efetivação a Agricultura Familiar Orgânica AFO, que influência na qualidade da alimentação escolar e, consequentemente, reflete-se na aprendizagem. O termo sustentabilidade é utilizado neste estudo como sinônimo de desenvolvimento sustentável, que harmoniza os aspectos socioeconômicos com 0 aspecto ambiental, trazendo a questão para o fato de que a Lei da Merenda Escolar, ao tempo em que defende a aplicação da sustentabilidade ambiental, defende, também, o desenvolvimento econômico da agricultura familiar - AF. Seguindo os preceitos da AF no Programa Nacional de Alimentação Escolar - PNAE, a recomendação é de que se volte à atenção para os produtos orgânicos ou da agroecologia. Porém, apesar da Lei recomendar a aplicação basilar da sustentabilidade, esta proposta ainda é muito tímida na sua efetivação, vez que a própria Lei não cria condições para que se efetive.

Palavras-chave: Agricultura Familiar; Alimentação Orgânica; Efetividade do PNAE.

\section{THE PRINCIPLE OF SUSTAINABILITY IN THE SCHOOL SCHEME LAW}

\begin{abstract}
Within the perspective of sustainability as a constitutional, fundamental and social principle, a bibliographical revision was made on themes that deal with the School snack Law and the Principle of Sustainability, and the incidence of this principle in the provisions of the text of the Law, presenting as one of the alternatives for its implementation of Organic Family Farming - AFO, which influences the quality of school feeding and, consequently, is reflected in learning. The term sustainability is used in this study as a synonym of sustainable development, which harmonizes the socioeconomic aspects with the environmental aspect, bringing the issue to the fact that the School snack Law, while defending the application of environmental sustainability, also, the economic development of family agriculture - AF. Following the precepts of FA in the National School Feeding Program - PNAE, the recommendation is to focus on organic products or agroecology. However, although the Law recommends the basic application of sustainability, this proposal is still very timid in its implementation, since the Law itself does not create conditions for it to take effect.
\end{abstract}

Keywords: Family farming; Organic Food; Effectiveness of PNAE. 


\section{INTRODUÇÃO}

O crescente debate acerca da sustentabilidade dos recursos naturais, por conta do modelo de desenvolvimento que põe em risco todo tipo de vida que habita a biosfera, coloca em evidência diversos setores da sociedade, a exemplo do setor alimentício, do qual oriunda a alimentação escolar, que deve harmonizar-se com o princípio da sustentabilidade, conforme está previsto na Lei 11.947, de 16 de junho de 2009 ou Lei da Merenda Escolar (BRASIL, 2009a).

Para Silva (2011), o princípio da sustentabilidade tem fundamento constitucional, previsto no artigo 225 da Carta Magna, quando impõe ao poder público e à coletividade o dever de defender e preservar o direito ao meio ambiente ecologicamente equilibrado para as atuais e futuras gerações, sendo que até mesmo a jurisprudência do Superior Tribunal Federal - STF reconhece o desenvolvimento sustentável, usado como sinônimo de sustentabilidade, como princípio de ordem constitucional.

Ainda, "os princípios são ordenações que se irradiam e imantam os sistemas de normas" (SILVA, 2009, pág.92). Isso demonstra que a Lei Maior reconhece a sustentabilidade como um princípio, uma base da qual emanam outros dispositivos e documentos legais, ou seja, serve de fundamento, é pedra fundante dos estudos sobre a temática ambiental.

Conforme legislação que trata da Educação Ambiental - Lei 9.795 (BRASIL, 1999), um dos princípios desse ramo do saber é a concepção de meio ambiente em sua totalidade, considerando interdependência entre o meio natural, o socioeconômico e o cultural, sob o enfoque da sustentabilidade. Isso demonstra que a Lei infraconstitucional também adotou a sustentabilidade como princípio, no viés da educação relacionada ao meio ambiente.

A sustentabilidade é a concepção do uso racional e limitado dos recursos naturais, a fim de evitar o esgotamento da matéria prima desde o processo de produção, passando pelo consumo sustentável até o descarte desses recursos (CARVALHO, 2013). Logo, é necessária uma relação harmoniosa entre homem-natureza de modo a garantir a permanência dos elementos naturais vivos e não vivos do meio ambiente.

Dentro dessa perspectiva, a Lei da Merenda Escolar, mais conhecida como Programa Nacional de Alimentação Escolar - PNAE apresenta várias recomendações para que o princípio da sustentabilidade seja aplicado na produção, aquisição, distribuição e consumo da merenda escolar, na garantia, no mínimo, de uma refeição diária aos alunos matriculados em escolas públicas e filantrópicas.

O PNAE dispõe sobre o atendimento da alimentação escolar e do Programa Dinheiro Direto na Escola - PDDE aos alunos da educação básica, sendo estes divididos entre alunos da Educação Infantil, Fundamental I e II, Ensino Médio em todas as suas modalidades e Educação de Jovens e Adultos - EJA, das escolas públicas, filantrópicas e conveniadas com o poder público.

A referida Lei é mais bem explicada pelo Fundo Nacional do Desenvolvimento Educacional - FNDE, através da Resolução № 26 de junho de 2013 (BRASIL, 2013), que corrobora a presença 
do princípio da sustentabilidade na merenda escolar, ao dispor sobre o atendimento da alimentação escolar aos alunos da educação básica no âmbito do PNAE.

Dentre as diretrizes da alimentação escolar, merece destaque o apoio ao desenvolvimento sustentável, ao pregar que a alimentação escolar deve estar pautada na nutrição adequada, através de alimentos variados, regionais e também na produção sustentável (BRASIL, 1999). Assim, o PNAE apresenta-se como instrumento motivador da sustentabilidade ambiental ao propor, também, a produção sustentável.

Uma das alternativas apresentadas pela Lei para a produção sustentável é a Agricultura Familiar Orgânica - AFO, entendida como uma forma de produção que se utiliza predominantemente da mão-de-obra familiar na execução das atividades agropecuárias de forma a conservar os recursos naturais e sem prejudicar o meio ambiente. Dessa forma, a produção orgânica é uma alternativa para a AF no perfeito intercâmbio entre os aspectos sociais, ambientais e econômicos, corroborando a sustentabilidade e a valorização dos produtos oriundos da agricultura familiar (CASTRO NETO et al., 2010).

O termo sustentável aparece várias vezes no decorrer do texto da Lei, sendo entendido, pelo contexto em que se apresenta, como a transformação e otimização de uma série de resultados agronômicos, ambientais e socioeconômicos dos sistemas agrícolas desde o rendimento das culturas, até a biodiversidade e a nutrição (MOSSMANN e TEO, 2017). Ou como os usos racionais dos recursos naturais de forma a garanti-los para as presentes e futuras gerações (RASHIDI et al., 2015). Ou, ainda, o desenvolvimento sustentável atrelado ao bem-estar humano, social e ambiental (KANTER et al., 2018).

Além do requisito da sustentabilidade, O PNAE também se preocupa com a nutrição do estudante no período de aulas e incentiva a promoção de bons hábitos alimentares. Atende preferencialmente escolas públicas, fornecendo aos estudantes $20 \%$ das necessidades nutricionais diárias, contribuindo para o crescimento saudável, desenvolvimento biopsicossocial e melhor rendimento escolar (PAIVA et al., 2016).

Nesse contexto, esta pesquisa documental, realizada com base nas leis e normas de ordenamento jurídico, artigos científicos selecionados através da busca pelas palavras-chave: Agricultura Familiar, Alimentação Orgânica e PNAE, nas bases de dados Scielo, Google Acadêmico e Science Direct, tem como objetivo uma análise e discussão de como a sustentabilidade se apresenta dentro PNAE, com base na agricultura familiar orgânica para a efetivação de tal princípio, de modo a atender o direito do acesso a uma merenda escolar saudável com efetiva e consequente melhoria no processo de aprendizagem.

\section{O direito à alimentação escolar e o princípio da sustentabilidade na lei da merenda escolar}

O direito à alimentação de uma forma geral encontra-se positivado na Carta Magna, artigo 6ํㅡ, ao estabelecer que são direitos sociais a educação, a saúde, a alimentação, o trabalho, a 
moradia, o lazer, a segurança, a previdência social, a proteção à maternidade e à infância, a assistência aos desamparados, na forma da Constituição (BRASIL, 1988).

Por direitos sociais compreendem-se aqueles que tratam de atender às necessidades dos indivíduos, e são alçados à categoria de direito fundamental, sendo estes definidos como situações jurídicas sem as quais a pessoa não se realiza, não convive e, às vezes, nem mesmo sobrevive (SILVA, 2009).

Para Araújo e Nunes Júnior (2005), os direitos fundamentais são princípios jurídicos que concretizam o respeito à dignidade humana, seja numa dimensão subjetiva, provendo as pessoas de bens e posições jurídicas favoráveis e invocáveis perante o estado e terceiros, seja numa dimensão objetiva servindo como parâmetro conformador do modelo de Estado. Os direitos sociais são direitos fundamentais que resguardam o homem nas suas necessidades.

Dessa forma, o direito à alimentação é um direito fundamental social, ou seja, é um direito básico que advém da condição se ser humano, que precisa ter suas necessidades supridas. Assim, se o direito à alimentação é um direito fundamental social, na modalidade escolar, também o é, juntamente com outros direitos, conforme previsão da Carta Magna ao determinar que é dever do Estado garantir a educação por meio de programas suplementares de material didático escolar, transporte, alimentação e assistência à saúde (BRASIL, 1988).

Ademais, a alimentação escolar é um direito do aluno e um dever do Estado, conceituada como todo alimento oferecido no ambiente escolar, independentemente de sua origem, durante o período letivo, Lei 11.947/ 2009, artigos $1^{\circ}$ e $3^{\circ}$, (BRASIL, 2009a). Foi ampliada para toda a Educação Básica depois da emenda 59 de 11 de novembro de 2009 (BRASIL, 2009b), vez que, antes disso, a merenda escolar deixava de fora os alunos do ensino médio e da EJA (Educação de Jovens e Adultos). Atualmente, qualquer aluno matriculado em escola pública, filantrópica e em entidades comunitárias (conveniadas com o poder público) tem direito à merenda escolar.

A Lei da Merenda Escolar traz como uma de suas diretrizes a sustentabilidade, ao preceituar que uma das bases políticas da alimentação escolar é o apoio ao desenvolvimento sustentável, com incentivos para a aquisição de gêneros alimentícios diversificados, produzidos em âmbito local e preferencialmente pela agricultura familiar e pelos empreendedores familiares rurais, priorizando as comunidades tradicionais indígenas e de remanescentes de quilombos, conforme consta na Lei 11.947/2009, art. $2^{\circ}$, inciso V (BRASIL, 2009a). Com isso, a Lei valoriza a economia local e o equilíbrio do meio ambiente.

Para Kanter et al. (2018), a agricultura sustentável é um dos segmentos agrícolas mais vibrantes, resilientes e produtivos; é fundamental para alcançar os objetivos do desenvolvimento econômico sustentável. Este, trata de transformar e exige aperfeiçoar uma série de resultados agronômicos, ambientais e socioeconômicos dos sistemas agrícolas, desde o rendimento das culturas até a biodiversidade e a nutrição humana. Assim, chama-se à atenção para o fato de que não importa somente alimentar, é preciso saber sobre a origem dos alimentos, como é feito e por 
quem é feito todo o processo até chegar às escolas. Não se pode olvidar que a agricultura desempenha um papel central no desenvolvimento sustentável. Sua posição é fundamental como fornecedora de nutrição humana, porque molda a economia global e a relação da sociedade com o mundo natural (KANTER, 2018).

A Lei determina que os cardápios da alimentação escolar devem ser elaborados pelo nutricionista responsável, com a utilização de gêneros alimentícios básicos, respeitando-se as referências nutricionais, os hábitos alimentares, a cultura e a tradição alimentar da localidade, pautando-se na sustentabilidade e diversificação agrícola da região, na alimentação saudável e adequada, Lei 11.947, 2009, art. 12 (BRASIL, 2009a). Mais uma vez, o texto da Lei chama à atenção para a sustentabilidade na alimentação escolar.

Outrossim, a norma direciona os recursos financeiros repassados pelo FNDE, no âmbito do PNAE, com mínimo de 30\% (trinta por cento) deste recurso, destinados para a aquisição de gêneros alimentícios diretamente da agricultura familiar e do empreendedor familiar rural ou de suas organizações, priorizando-se os assentamentos da reforma agrária, as comunidades tradicionais indígenas e comunidades quilombolas (BRASIL. Lei 11.947, 2009, art. 14).

Com isso, 30\% do valor repassado pelo PNAE devem ser investidos na compra direta de produtos da $\mathrm{AF}$, medida que estimula o desenvolvimento econômico, porém, não torna obrigatório o fornecimento de alimentos orgânicos, deixando a sustentabilidade, em sua essência, relegada a segundo plano, o que enfraquece o requisito da sustentabilidade preceituado na própria Lei.

De acordo com a Resolução 4/2015 do FNDE/MEC (BRASIL, 2015), na impossibilidade de realização de pesquisa de preços de produtos agroecológicos ou orgânicos, poderão ser acrescidos aos preços desses produtos até 30\% (trinta por cento) em relação aos preços estabelecidos para produtos convencionais. Isso deixa de ser um atrativo para quem compra, pois a Lei não majora o capital para a compra dos orgânicos, manda apenas que retire do montante disponível para os alimentos convencionais 30\% a mais, caso se compre alimentos orgânicos.

Para a efetividade das diretrizes da Lei da merenda - PNAE os sistemas educacionais devem criar seus Conselhos de Alimentação Escolar - CAE, tendo como competência, dentre outras, zelar pela qualidade dos alimentos, em especial quanto às condições higiênicas, bem como a aceitabilidade dos cardápios oferecidos. Conta-se, ainda, com o acompanhamento e fiscalização pela sociedade, e também pelo FNDE, pelo Tribunal de Contas da União - TCU, pela Controladoria Geral da União - CGU e pelo Ministério Público, Lei 11.947/2009 (BRASIL, 2009a). Nesse diapasão, todos os institutos acima referenciados são partes legítimas para fazer valer o princípio da sustentabilidade no programa de alimentação escolar.

Outro documento legal que enfatiza o princípio da sustentabilidade na Lei da alimentação escolar é a Resolução no 26, de 17 de novembro de 2013, do Conselho do Fundo Nacional de Desenvolvimento da Educação, ao estabelecer as normas para a execução técnica, administrativa e financeira do PNAE aos Estados, ao Distrito Federal, aos Municípios e às entidades federais. 
O artigo 13 dessa resolução determina que, para fins do PNAE, será considerado Educação Alimentar e Nutricional - EAN o conjunto de ações formativas, de prática contínua e permanente, transdisciplinar, intersetorial e multiprofissional, que objetiva estimular a adoção voluntária de práticas e escolhas alimentares saudáveis que colaborem para a aprendizagem, o estado de saúde do escolar e a qualidade de vida do indivíduo.

O parágrafo $1^{\circ}$ desse mesmo artigo, no seu inciso VII, deixa claro que entidades executoras poderão considerar ações de EAN, aquelas que estimulem e promovam a utilização de produtos orgânicos e/ou agroecológicos e da sociobiodiversidade. Nessa passagem do texto, o simples comando "poderão" deixar de ser uma prioridade para se tornar opção. Para a efetividade da sustentabilidade o termo ideal seria "deverão" em vez de "poderão".

Os cardápios da alimentação escolar deverão ser elaborados pelo Responsável Técnico (RT), com utilização de gêneros alimentícios básicos, de modo a respeitar as referências nutricionais, os hábitos alimentares, a cultura alimentar da localidade e pautar-se na sustentabilidade, sazonalidade e diversificação agrícola da região e na alimentação saudável e adequada (BRASIL/FNDE - Resolução n 26, 2013, art.14).

Para facilitar a compra dos alimentos da agricultura familiar poderá ser dispensando o procedimento licitatório, desde que os preços sejam compatíveis com os vigentes no mercado local, observando-se os princípios inscritos no art. 37 da Constituição Federal, e que os alimentos atendam às exigências do controle de qualidade estabelecidas pelas normas que regulamentam a matéria (BRASIL/FNDE. Resolução ํำ 26, 2013, art.14, \& 1ำ).

O critério de prioridade na aquisição de alimentos da agricultura familiar será dado, sucessivamente, ao grupo de projetos de fornecedores locais, grupo de projetos do território rural, grupo de projetos do estado, e grupo de propostas do País (BRASIL/FNDE - Resolução nํ26, 2013, art.25, \& 1ํ). Em cada grupo de projetos, é observada a seguinte ordem de prioridade para seleção: os assentamentos de reforma agrária, as comunidades tradicionais indígenas e as comunidades quilombolas, não havendo prioridade entre estes.

Em seguida, a prioridade é dada aos fornecedores de gêneros alimentícios certificados como orgânicos ou agroecológicos, (BRASIL/ FNDE - Resolução oำ26, 2013, art.14, \& 2º). Logo, observase, mais uma vez, o alinhamento da merenda escolar ao princípio da sustentabilidade ao priorizar a seleção de alimentos orgânicos. A máxima expressão do princípio da sustentabilidade na merenda escolar encontra-se positivado na Resolução em comento, ao preceituar que as aquisições realizadas no âmbito do PNAE visam contribuir para o desenvolvimento local e sustentável (BRASILFNDE - Resolução 26/2013, art. 69).

Isso mostra que a Lei da Merenda Escolar defende uma sustentabilidade aliada ao desenvolvimento econômico, com a consequente priorização da agricultura familiar e a recomendação da produção de orgânicos. 


\section{Importância da alimentação escolar no processo de aprendizagem}

O PNAE priorizou inicialmente as regiões mais pobres, onde o índice de desnutrição era maior, considerando que a merenda escolar é de extrema importância no processo de ensinoaprendizagem, assumindo uma função significativa em práticas educativas e campanhas de promoção a saúde, propondo melhores condições nutricionais resultando em uma aprendizagem significativa (LIBERMANN e BERTOLINI, 2015).

O Programa destaca-se pelo tempo de atuação, sendo considerado o maior programa de alimentação escolar da América Latina, avaliando os aspectos de seu atendimento, expansão, reformulações, etc., instituindo estratégia de Segurança Alimentar e Nutricional (SAN), ao requerer o Direito Humano a Alimentação Adequada (DHAA) através da merenda escolar (LIBERMANN e BERTOLINI, 2015; CESAR et al., 2018).

Ao longo do tempo, o PNAE sofreu algumas modificações e alterações para melhor atender a demanda da merenda escolar, integrando a políticas de direito à alimentação e de produção agrícola, adquirindo alimentos da agricultura familiar como uma fonte de alimentos mais natural e menos processada, além de promover o desenvolvimento econômico do agricultor familiar (TRICHES et al., 2016).

Desse modo, é importante ressaltar que a escola conheça a realidade do aluno, bem como cultura e modos de vida, adaptando o cardápio ao mesmo para não causar choques e rejeição da merenda escolar (GOMES, 2016). Em determinados casos, a escola enfrenta alguns desafios na oferta de alimentos por estar relacionado intrinsecamente com educação alimentar a desperdícios de alimentos.

\section{Agricultura familiar e sustentabilidade}

A agricultura familiar é uma forma de produção que se utiliza predominantemente da mãode-obra familiar na execução das atividades agropecuárias (MIRANDA e GOMES, 2016). Dessa forma, apresenta uma dinâmica diferente da não familiar por apresentar uma relação particular de trabalho.

O Decreto 9.064, de 31 de maio de 2017 (BRASIL, 2017), que, entre outras funções, regulamenta a Lei da Agricultura Familiar, Lei $\mathrm{n} \cong$ 11.326, de 24 de julho de 2006 (BRASIL, 2006), determina em seu artigo $3^{\circ}$, que para ser considerado agricultor ou agricultora familiar, existem quatro critérios, quais sejam:

\footnotetext{
I - possuir, a qualquer título, área de até quatro módulos fiscais;

II - utilizar, no mínimo, metade da força de trabalho familiar no processo produtivo e de geração de renda;

III - auferir, no mínimo, metade da renda familiar de atividades econômicas do seu estabelecimento ou empreendimento; e

IV - ser a gestão do estabelecimento ou do empreendimento estritamente familiar.
} 
Como se vê, legalmente, a agricultura familiar encontra-se determinada por um limite de terra, de mão de obra, de renda e de gestão, o que acaba gerando óbice ao alargamento da produção. Mesmo não sendo expansiva em termos de quantidade, hodiernamente, a agricultura familiar representa um setor de destaque na economia do país, pois fornece renda para os pequenos agricultores, diminui o êxodo rural e ainda pode desenvolver-se dentro das práticas da sustentabilidade, ao aliar equilíbrio econômico, ambiental e social, caso opte pela agricultura orgânica.

Considera-se sistema de produção agropecuária o que adota técnicas específicas, mediante a otimização do uso dos recursos naturais e socioeconômicos disponíveis e o respeito à integridade cultural das comunidades rurais, tendo por objetivo a sustentabilidade econômica e ecológica, a maximização dos benefícios sociais, a minimização da dependência de energia não-renovável, empregando, sempre que possível, métodos culturais, biológicos e mecânicos (BRASIL, Lei 10.831, 2003, art. $\left.1^{\circ}\right)$.

Esses métodos obedecem a critérios que são em contraposição ao uso de materiais sintéticos a eliminação do uso de organismos geneticamente modificados e radiações ionizantes, em qualquer fase do processo de produção, processamento, armazenamento, distribuição e comercialização, e a proteção do meio ambiente (BRASIL, Lei 10.831, 2003, art.1ํ).

Ademais, considera-se produto da agricultura orgânica ou produto orgânico, seja ele in natura ou processado, aquele obtido em sistema orgânico de produção agropecuário ou oriundo de processo extrativista sustentável e não prejudicial ao ecossistema local (BRASIL, Lei 10.831, 2003, art. $\left.2^{\circ}\right)$. Nesse aspecto, a agricultura familiar pode desenvolver-se dentro da perspectiva da agricultura orgânica, o que vai ao encontro do princípio da sustentabilidade ambiental tanto na relação com a fauna como com a flora em todo sistema produtivo desses bens.

Dentro da perspectiva da sustentabilidade, a agricultura familiar destinada ao cultivo e comercialização de produtos orgânicos no Brasil vem crescendo gradativamente, embora ainda predomine a produção não sustentável. Segundo o IPEA (2012), a demanda por produtos orgânicos cresce em torno de $30 \%$ ao ano e estima-se, para o caso do Brasil, que $90 \%$ da produção orgânica sejam provenientes da agricultura familiar (PADUA et al., 2013).

No entanto, ainda existem muitos entraves para o desenvolvimento dos orgânicos na agricultura familiar. De acordo com Pádua (2013), mesmo com a agricultura familiar mantendo a força e grande representatividade na riqueza do país, os agricultores são penalizados por insuficiências de terras e capital, por dificuldades no financiamento, pela baixa disponibilidade tecnológica, assim como pela fragilidade da assistência técnica.

Assim, depreende-se que o princípio da sustentabilidade efetiva-se dentro da agricultura familiar quando se adota a preferência pelos sistemas orgânicos na sua produção para a comercialização, uma vez que a produção é cultivada organicamente, isto é, tem como objetivo 
produzir alimentos com valor nutricional equilibrado e isentos de venenos cujo consumo se relaciona com a promoção da saúde humana (PESSOA et al., 2014).

\section{METODOLOGIA}

Nesse contexto, esta pesquisa documental, realizada com base nas leis e normas de ordenamento jurídico, artigos científicos selecionados através da busca pelas palavras-chave: Agricultura Familiar, Alimentação Orgânica e PNAE, nas bases de dados Scielo, Google Acadêmico e Science Direct, tem como objetivo uma análise e discussão de como a sustentabilidade se apresenta dentro PNAE, com base na agricultura familiar orgânica para a efetivação de tal princípio, de modo a atender o direito do acesso a uma merenda escolar saudável com efetiva e consequente melhoria no processo de aprendizagem.

A seleção baseou-se, em grande parte, de artigos publicados de 2012 a 2018, dados que apresentam caracteres mais recentes sobre a problemática abordada, bem como livros jurídicos mais antigos, porém necessários em virtude da necessidade de definição de alguns termos. Enfatizou-se a Lei da Merenda Escolar e o princípio da sustentabilidade, sendo apresentadas algumas propostas de como este princípio efetiva-se dentro da lei da merenda escolar e quais os óbices encontrados na própria lei e fora dela para tal desígnio.

\section{RESULTADOS E DISCUSSÕES}

A lei da merenda escolar ou PNAE traz no seu bojo o princípio da sustentabilidade, sendoo recomendado de maneira enfática em vários dos seus dispositivos. Sugere como um meio para efetivar a sustentabilidade a agricultura familiar orgânica. Ao mesmo tempo em que destaca a importância da participação da agricultura familiar nesse processo, através dos alimentos orgânicos, também defende o desenvolvimento econômico desse setor agrícola.

Dessa forma, o desenvolvimento sustentável na agricultura familiar aparece como possibilidade da produção orgânica. Castañeda (2012) confirma que essa relação entre produção e a compra de alimentos orgânicos e o meio ambiente aparece como uma forma de os consumidores incentivarem a produção de alimentos em uma cadeia sustentável, com práticas agrícolas ecológicas, que não agridem o ambiente.

A preocupação com a qualidade alimentar e com o desenvolvimento rural são fatores para grandes discussões, atendendo às necessidades emergentes e preocupando-se com as gerações futuras (CARVALHO, 2017). A alimentação favorece a modificação de hábitos alimentares por disponibilizar novos alimentos que incentivem a segurança alimentar dentro de implicações higiênicas, nutricionais e funcionais (CARVALHO, 2017).

Para Gomes (2016), a alimentação saudável resulta em boa saúde e ajuda no processo de aprendizagem, balanceada dentro dos principais nutrientes da cadeia alimentar. Desse modo, é 
pertinente que os alimentos fornecidos nas escolas provenham da agricultura familiar a partir de técnicas orgânicas garantindo uma segurança alimentar e boa qualidade de vida.

No entanto, apesar do avanço da produção e comercialização dos alimentos orgânicos, ainda é muito pouca a procura pela sociedade em geral e pelos estabelecimentos escolares. Podese atribuir a isso a falta de educação alimentar nas escolas para estimular as pessoas ao consumo de alimentos saudáveis em toda a sua cadeia produtiva; a burocracia na certificação orgânica dos produtos da agricultura familiar e o elevado custo dos alimentos orgânicos (SANTOS et al., 2014).

Além disso, a própria Lei da merenda Escolar cria dificuldades à implantação da agricultura orgânica ao colocar alguns dispositivos legais como opção e não como prioridade, e em não fornecer verbas suficientes para a compra de alimentos mais caros e de melhor qualidade, a exemplo dos orgânicos. Tais desafios minimizam a aplicação da lei, vez que, ao não tornar obrigatória a compra de alimentos orgânicos e, sim, mera faculdade, dá liberdade aos dirigentes escolares de comprarem qualquer tipo de alimento.

Ademais, contribui para a inoperância da sustentabilidade a falta de investimentos financeiros por parte do Poder Público, que determina a compra de alimentos mais caros com a mesma quantia de capital usada para a compra de alimentos convencionais. Não se pode comprar produtos de maior qualidade com a mesma verba destinada aos produtos comuns e na mesma quantidade destes.

\section{CONSIDERAÇÕES FINAIS}

É cediço que o PNAE apresenta propostas e diretrizes que se coadunam com uma nutrição voltada a suprir os índices calóricos do estudante durante o tempo em que ele permanece na escola, tendo como princípio o da sustentabilidade, que pode se efetivar através da agricultura familiar, com a produção e comercialização dos produtos orgânicos. Porém, a própria Lei mitiga tal princípio.

Ao colocar em seus dispositivos comandos como "pode" em vez de "deve", a legislação que trata da merenda escolar oferece a sustentabilidade como opção e não como obrigação. Ainda, a própria Lei não cria condições para que os gestores escolares possam adquirir produtos orgânicos através de capital suficiente para isso. Não basta só querer comprar produtos orgânicos. É necessário, também, que haja maior estímulo a educação alimentar nas escolas, a desburocratização na entrega dos certificados orgânicos para os pequenos agricultores aderirem aos orgânicos e maior disponibilidade de verba para a compra de alimentos de qualidade e sustentáveis.

De fato, agricultura familiar orgânica é uma proposta sustentável e saudável que vincula ao hábito alimentar uma estratégia positiva no âmbito do desenvolvimento rural, ambiental e educacional, porém, precisa-se redirecionar a norma e atitudes para o efetivo intercâmbio entre os aspectos humanos, sociais e ambientais que permeiam a sustentabilidade. 


\section{REFERÊNCIAS}

ARAÚJO, L. A. D.; NUNES JÚNIOR, V. S. Curso de Direito Constitucional. São Paulo: Saraiva, 9. edição. 2005.

BRASIL. CONSTITUIÇÃO DA REPÚBLICA FEDERATIVA DO BRASIL DE 1988. Disponível em: www.planalto.gov.br. Acesso em: 30 abr. 2018.

BRASIL. Senado Federal. Lei no 9.795, de 27 de abril de 1999. Dispõe sobre a educação ambiental, institui a Política Nacional de Educação Ambiental e dá outras providências. Disponível em: http://www.planalto.gov.br/ccivil_03/leis//9795.htm. Acesso em: 30 abr. 2018.

BRASIL. Planalto. Lei ํㅡ. ำ 10.831, de 23 de dezembro de 2003. Dispõe sobre a agricultura orgânica e dá outras providências. Disponível em: http://www.planalto.gov.br/ccivil_03/Leis/2003/L10.831.htm. Aceso em: 05 mai. 2018.

BRASIL. Planalto. Lei no 11.326, de 24 de julho de 2006. Estabelece as diretrizes para a formulação da Política Nacional da Agricultura Familiar e Empreendimentos Familiares Rurais. Disponível em: http://www.planalto.gov.br/ccivil_03/_ato20042006/2006/lei/l11326.htm. Acesso em: 26 mar. 2018.

BRASIL. Planalto. Lei ํo. 11.947, de 16 de junho de 2009a. Dispõe sobre o atendimento da alimentação escolar e do Programa Dinheiro Direto na Escola aos alunos da educação básica. Disponível em: http://www.planalto.gov.br/ccivil_03/_ato20072010/2009/lei/l11947.htm. Acesso em: 26 mar. 2018.

BRASIL. EMENDA CONSTITUCIONAL № 59, DE 11 DE NOVEMBRO DE 2009b. Disponível em: http://www.planalto.gov.br/ccivil_03/constituicao/emendas/emc/emc59.htm. Acesso em: 30 abr. 2018.

BRASIL. Resolução no 26, de 17 de junho de 2013-FNDE. Dispõe sobre o atendimento da alimentação escolar aos alunos da educação básica no âmbito do Programa Nacional de Alimentação Escolar - PNAE. Disponível em: http://www.fnde.gov.br/acessoainformacao/institucional/legislacao/item/4620-resolu\%C3\%A7\%C3\%A3o-cd-fnden\%C2\%BA-26,de-17-de-junho-de-2013. Acesso em: 05 maio 2018.

BRASIL. Planalto. Decreto o 9.064, de 31 de maio de 2017. Dispõe sobre a Unidade Familiar de Produção Agrária, institui o Cadastro Nacional da Agricultura Familiar e regulamenta a Lei no 11.326, de 24 de julho de 2006, que estabelece as diretrizes para a formulação da Política Nacional da Agricultura Familiar e empreendimentos familiares rurais. Disponível em: http://www.planalto.gov.br/ccivil_03/_ato2015-2018/2017/decreto/D9064.htm. Acesso em: 06 ago. 2018.

BRASIL. Resolução no 4, de 3 de abril de 2015-FNDE/MEC. Altera a redação dos artigos 25 a 32 da Resolução/CD/FNDE nํ 26, de 17 de junho de 2013, no âmbito do Programa Nacional de Alimentação Escolar (PNAE). Disponível em: http://www.fnde.gov.br/resolucoes/2015. Acesso em: 05 maio 2018.

CARVALHO, A. P. L. S. Importância da Alimentação para Melhorias na Aprendizagem de Crianças em Unidades de Políticas de Ensino: revisão integrativa. Revista SOMMA, v. 2, n. 2, p. 74-83, 2017.

CARVALHO, D. M. Consumo sustentável como fator determinante para a sustentabilidade. Conteúdo Jurídico, Brasília - DF: 06 jul. 2013. Disponível em: http://www.conteudojuridico.com.br/?artigos\&ver=1055.44280\&seo=1. Acesso em: 08 maio 2018.

CASTAÑEDA, M. Ambientalização e politização do consumo nas práticas de compra de orgânicos. Cad. CRH, vol.25, n.64, Salvador Jan./Apr. 2012. 
CASTRO NETO, N.; DENUZI, V. S. S.; RINALDI, R. N.; STADUTO, J. R. Produção orgânica: uma potencialidade estratégica para a agricultura familiar. Revista Percurso, 2(2), 73-95, 2010.

CESAR, J. T.; VALENTIM, E. D. A; ALMEIDA, C. C. B; SCHIEFERDECKER, M. E. E; SCHMIDT, S. T. Alimentação Escolar no Brasil e Estados Unidos: uma revisão integrativa. Ciência e Saúde Coletiva, 23(3), 991-1007, 2018.

GOMES, W. S. T. Alimentação Escolar Saudável. 2016. 54f. Trabalho de Conclusão de Curso TCC (Licenciatura em Educação do Campo) - Universidade de Brasília, Brasília, 2016.

KANTER, D. R.; MUSUMBA, M.; WOOD, S. L. R.; PALM, C.; ANTLE, J.; BALVANERA, P.; DALE, V. H.; HAVLIK, P.; KLINE, K. L.; SCHOLES, R. J.; THORNTON, P.; TITTONELL, P.; ANDELMAN, $\mathrm{S}$. Evaluating agricultural trade-offs in the age of sustainable development. Agricultural Systems, 163, 73-88, 2018.

LIBERMANN, A. P.; BERTOLINI, G. R. F. Tendências de pesquisa em políticas públicas: uma avaliação do Programa Nacional de Alimentação Escolar - PNAE. Ciência e Saúde Coletiva, 20(11), 3533-3546, 2015.

MIRANDA, D. L. R.; GOMES, B. M. A. Programa nacional de fortalecimento da agricultura familiar: trajetórias e desafios no Vale do Ribeira, Brasil. Sociedade e Natureza, 28(3), 397-408, 2016.

MOSSMANN P. M; TEO. R. P. A. C. Alimentos da agricultura familiar na alimentação escolar: percepções dos atores sociais sobre a legislação e sua implementação. Interações (Campo Grande), 18(2), 31-43, 2017.

PADUA, J. B.; SCHLINDWEIN, M. M.; GOMES, E. P. Agricultura familiar y la agricultura ecológica: un análisis comparativo teniendo en cuenta los datos del censo de 1996 y 2006. Interações (Campo Grande), 14(2), 225-235, 2013.

PAIVA, J. B.; FREITAS, M. C. S.; SANTOS, L. A. S. Significados da alimentação escolar segundo alunos atendidos pelo Programa Nacional de Alimentação Escolar. Ciência e Saúde Coletiva, 21(8), 2507-2516, 2016.

PESSOA, Y. S. R. Q.; ALCHIERI, J. C. Qualidade de vida em agricultores orgânicos familiares no interior Paraibano. Psicologia: Ciência e Profissão, 34(2), 330-343, 2014.

RASHIDI, H. R.; HOSEINI, A. G.; HOSEINI, A. G.; SULAIMAN, N. M. N.; TOOKEY, J.; HASHIM, N. A. Application of wastewater treatment in sustainable design of green built environments: A review. Journal Renewableand Sustainable Energy Reviews. 49, 845-856, 2015.

SANTOS, F.; FERNANDES, P. F.; ROCKETT, F. C. OLIVEIRA, A. B. A. Avaliação da inserção de alimentos orgânicos provenientes da agricultura familiar na alimentação escolar, em municípios dos territórios rurais do Rio Grande do Sul, Brasil. Ciência e Saúde Coletiva, 19(5), 1429-1436, 2014.

SILVA, J. A. Curso de Direito Constitucional Positivo. 32 ed. rev., atual. e ampl., São Paulo: Malheiros, 2009.

SILVA, J. A. Direito Ambiental Constitucional. 9aㅗ ed. São Paulo: Malheiros, 2011.

TRICHES, R. M.; BARBOSA, L. P.; SILVESTRE, F. Agricultura familiar e Alimentação Escolar no Estado do Paraná: uma análise das chamadas públicas. Revista Paranaense de Desenvolvimento, 37(130), 29-43, 2016. 